\title{
Electroanalytical study of fluvoxamine
}

Henri P. A. Nouws, Cristina Delerue-Matos Aquiles, A. Barros, Jose' A. Rodrigues, Alice Santos-Silva

\begin{abstract}
Fluvoxamine (FVX) can be reduced at a mercury-drop electrode, with a maximum peak current intensity being obtained at a potential of $-0.7 \mathrm{~V}$ vs. $\mathrm{Ag} /$ $\mathrm{AgCl}$, in an aqueous electrolyte solution of $\mathrm{pH} 2$. The compound was determined in a pharmaceutical product and in spiked human serum by square-wave adsorptivestripping voltammetry (SWAdSV) after accumulation at the electrode surface, under batch conditions. Because the presence of dissolved oxygen did not interfere significantly with the analysis, it was also possible to determine FVX in the pharmaceutical product by use of a flow-injection analysis (FIA) system with SWAdSV detection. The methods developed were validated and successfully applied to the quantification of FVX in a pharmaceutical product. Recoveries between 76 and $89 \%$ were obtained in serum analysis. The FIASWAdSV method enabled analysis of up to 120 samples per hour at reduced cost, implying the possibility of competing with the chromatographic methods usually used for this analysis.
\end{abstract}

\section{Keywords}

Fluvoxamine, Square-wave adsorptive- stripping voltammetry, Flow-injection analysis, Electrochemical detection, Pharmaceuticals $\mathbb{E}$ Serum
Introduction

Fluvoxamine (FVX, Fig. 1), a selective serotonin re- uptake inhibitor (SSRI), is primarily used as an antide- pressant drug but is also used to treat other psycholog- ical problems, for example obsessive-compulsive, panic, and post-traumatic stress disorders.

For drug development and for treatment purposes it is very important to be able to quantify the drug, and occasionally its metabolites, in a wide variety of samples (serum, plasma, urine, and pharmaceutical products) to establish its pharmacokinetics, metabolic pathway, dosage, etc. This implies the need for analytical methods with high sample-throughput, low limits of detection, and low maintenance costs.

After administration, FVX is extensively metabolised in the liver, without formation of active metabolites, and only negligible amounts are excreted unchanged in the urine. Its concentration in blood is difficult to predict, because of high variability between individuals, and no therapeutic window has been established [1-3]. Thus, therapeutic drug monitoring might be helpful to im- prove therapy with FVX.

Most FVX analysis is performed by high-perfor- mance liquid chromatography (HPLC) coupled with spectrometric detectors, ultraviolet/diode array [4-17], mass spectrometric $[18,19]$ and fluorimetric [20-22], for analysis of pharmaceuticals [8] and human serum or plasma [4-7, 1022]. This widespread usage of HPLC methods is justified by the high sensitivity and the low limit of detection usually obtained and the possibility of simultaneous analysis of the drug and its metabolites, which increases its use even further. The main disad- vantages of HPLC are the relatively long analysis times and high acquisition and maintenance costs. Several other methods, based on electrophoresis [23, 24], micellar electrokinetic capillary chromatography [25], isotachophoresis [26], gas chromatography [27-30],

ultraviolet-visible [31-36], infrared [31], and nuclear magnetic resonance $[31,37]$ spectrometry, have also 



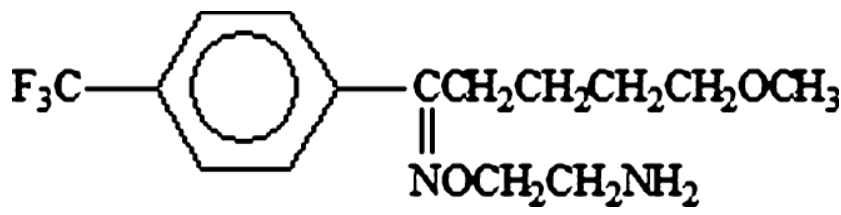

Fig. 1 Chemical structure of FVX

been described, mainly for determination of FVX in pharmaceutical products.

Electrochemical studies on the determination of FVX have also been reported [38-40]. All these studies focussed on the determination of the antidepressant in pharmaceutical products using either square-wave or differential-pulse polarography under batch conditions. Adsorptive-stripping voltammetry (AdSV) is a tech- nique mainly used for the analysis of organic com- pounds, which can be accumulated at, for example, the hanging mercury drop electrode (HMDE) surface and afterwards stripped off by applying a potential scan [41]. The introduction of highscan-rate voltammetric tech- niques, for example squarewave voltammetry (SWV), increases the sensitivity of AdSV even further [42, 43].

In this study electroanalytical procedures for the determination of FVX in a pharmaceutical product and in spiked human serum under batch conditions are presented. Furthermore, an alternative method for determination of FVX in a pharmaceutical product has also been developed by adapting a square-wave-strip- ping voltammetric method for use in a FIA system.

\section{Experimental}

\section{Apparatus}

Voltammetric measurements, using SWV and squarewave adsorptive-stripping voltammetry (SWAdSV), were performed using a Autolab PGSTAT12 (MetrohmEcoChemie) potentiostat, controlled by a PC by use of GPES 4.9 software from Metrohm-EcoChemie, and a Metrohm $663 \mathrm{VA}$ stand containing a three-electrode cell (all Metrohm). This voltammetric cell consisted of a multimode mercury working electrode, used in the static mercury-drop position (SMDE), an $\mathrm{Ag} / \mathrm{AgCl} / \mathrm{KCl}$ $3 \mathrm{~mol} \mathrm{~L}^{-1}$ reference electrode, and a glassy carbon auxiliary electrode. This system was used both under batch conditions and as the detector in the developed single FIA manifold.

In the FIA system the solutions were transported to the voltammetric detection cell by means of a Gilson Minipuls 3 peristaltic pump, using PTFE tubing (i.d.

$0.8 \mathrm{~mm})$. Samples and standards $\left(V_{\text {inj }}=500\right.$ lL) were introduced into the carrier stream through a six-port Rheodyne type 5041 injection valve.

In the voltammetric flow cell used [44] the glass capillary of the SMDE is inserted into a PTFE adapter head and the flow is directed toward the mercury drop.
This adapter head enables reproducible repositioning of the glass capillary whenever the flow cell is dismounted and then remounted. The adapter head, the reference electrode, and the counter-electrode are contained in a glass cell, which is filled with the solution used as the carrier stream. A drain ensures a constant level of solution is maintained during the work.

The comparative UV spectrophotometric method, using a Shimadzu UV-260 recording spectrophotometer, was developed internally by recording the absorption spectrum of a $5.0 \cdot 10^{-5}$ mol L ${ }^{-1} \mathrm{FVX}$ solution between 190 and $360 \mathrm{~nm}$. The absorbance peak at $245 \mathrm{~nm}$ was selected for quantification purposes.

\section{Reagents}

An FVX maleate standard was provided by Solvay Pharmaceuticals (Olst, The Netherlands) and used without further purification. Stock solutions of FVX were prepared by dissolution of precisely weighed amounts of the standard in water. These stock solutions were diluted with electrolyte solution to furnish the desired concentration. All other reagents, of p.a. quality, were purchased from Merck and Sigma-Aldrich. All solutions were prepared using deionised water (conductivity $<0.1 \mathrm{1S} \mathrm{cm}^{-1}$ ).

For optimisation of electrolyte $\mathrm{pH}$, several buffers, for example phosphate, acetate, and ammonium, were used to cover a wide $\mathrm{pH}$ range $(2-10)$. After optimisa- tion $\mathrm{pH} 2$ $\mathrm{H}_{3} \mathrm{PO}_{4} / \mathrm{H}_{2} \mathrm{PO}_{4}$ buffer $\left(0.1^{-} \mathrm{mol} \mathrm{L}\right)$ was used.

\section{Samples}

The pharmaceutical used for evaluation of the adequacy of the developed method was Dumyrox (Solvay Pharmaceuticals). This is currently the only commercially available FVX-containing pharmaceutical on the Portuguese market. The labelled value of FVX maleate per tablet is $50 \mathrm{mg}$. The tablets were weighed, finely powdered, and dissolved in $500.0 \mathrm{~mL}$ deionised water by sonication for $10 \mathrm{~min}$.

For batch analysis the resulting solution was diluted 100-fold with electrolyte. For quantification purposes, using the standard addition method, fixed volumes (117 1L) of the diluted sample solution were placed in five $20.00-\mathrm{mL}$ volumetric flasks and standard additions between 0 and $1.20 \cdot 10^{-8}$ mol $\mathrm{L}^{-1}$ were made by adding increasing quantities of FVX standard. The volume was completed with electrolyte and the contents of the volumetric flasks were transferred into a voltammetric cell and analysed.

For the standard addition method in the flow-injection technique six standards were prepared by placing 21.7-1L samples in $10.00-\mathrm{mL}$ volumetric flasks and standard additions between 0 and $1.00 \cdot 10^{-6} \mathrm{~mol} \mathrm{~L}^{-1}$ were made by adding increasing quantities of FVX standard. The volume was completed with electrolyte 
and the solutions were then injected directly into the FIA system.

For quantification by the comparative UV method five standard additions between 0 and $4.00 \cdot 10^{-5} \mathrm{~mol} \mathrm{~L}^{-1}$ were made to $1.000 \mathrm{~mL}$ of the sample solution contained in a $10.00-\mathrm{mL}$ volumetric flask. The volume was completed with water and the solutions were filtered before analysis.

Serum samples were obtained from healthy individuals who were not receiving treatment with $\mathrm{FVX}$, and analysed on the same day. This serum $(1.000 \mathrm{~mL})$ was spiked with an amount of FVX giving a concentration approximately five times the therapeutic level (1.6- $\left.10^{-6} \mathrm{~mol} \mathrm{~L}^{-1}\right)$. After shaking, $1.5 \mathrm{~mL} \mathrm{NH} \mathrm{mLl}_{4} \mathrm{CHH}$ buffer solution, $\mathrm{pH} 9.5$, was added. The mixture was shaken mechanically for $30 \mathrm{~s}$ then extracted with chloroform-2-isopropanol- $n$-heptane, 60:14:26 (v/v). After shaking for $2 \mathrm{~min}$ and centrifuging for $10 \mathrm{~min}$ at $2800 \mathrm{~g}$, the organic layer was transferred to another receptacle and evaporated under a stream of nitrogen [10]. The dried extract was dissolved in $5.000 \mathrm{~mL}$ electrolyte and a $923-\mathbf{1 L}$ portion was added to $20.00 \mathrm{~mL}$ electrolyte in the voltammetric cell to furnish a concentration of 1.5 $-10^{-8} \mathrm{~mol} \mathrm{~L}^{-1}$. Again, the standard addition method was used, and the additions, between 0 and $3.02 \cdot 10^{-8} \mathrm{~mol} \mathrm{\textrm {L } ^ { - 1 }}$, were made directly in the voltammetric cell.

\section{Validation procedure}

When the optimum experimental conditions had been found, validation of the methods was performed. For this purpose, the linear range, limit of detection (LOD), limit of quantification (LOQ), repeatability, intermedi- ate precision, recovery, and selectivity were evaluated [45].

The linear range was determined by analysing FVX solutions in the ranges $1.00 \cdot 10^{-9}$ to $1.00 \cdot 10^{-6} \mathrm{~mol} \mathrm{\textrm {L } ^ { - 1 }}$ and $1.00 \cdot 10^{-7}$ to $5.00 \cdot 10^{-5} \mathrm{~mol} \mathrm{~L}^{-1}$ for the SWAdSV and FIA-SWAdSV methods, respectively. The LOD and LOQ were calculated from the linear calibration plot [46].
Repeatability and intermediate precision were assessed at three concentrations. For the SWAdSV method concentration levels of $3.0 \cdot 10^{-8}, 1.0 \cdot 10^{-7}$, and $1.7 \cdot 10^{-7} \mathrm{~mol} \mathrm{~L}^{-1}\left(t_{\mathrm{acc}} 30 \mathrm{~s}\right)$ and $1.0 \cdot 10^{-8}, 4.0 \cdot 10^{-}$ 8 , and $8.0 \cdot 10^{-8} \mathrm{~mol} \mathrm{~L}^{-1}\left(t_{\mathrm{acc}} 60 \mathrm{~s}\right)$ were used. The preci- sion of the flow-injection method was evaluated by use of $2.0 \cdot 10^{-6}, 5.0 \cdot 10^{-6}$, and $8.0 \cdot 10^{-6} \mathrm{~mol} \mathrm{~L}^{-1}$ FVX

solutions. To assess the repeatability five replicate measurements of each solution were made in a short period of time. To determine intermediate precision the solutions were each analysed five times per day for three consecutive days.

The accuracy of the procedure was verified by performing recovery assays at three concentrations, in triplicate. In the evaluation of the SWAdSV method two preconcentration times were used ( $t_{\text {acc }} 30$ and $60 \mathrm{~s}$ ), and a solution of the pharmaceutical containing 2.0 $10^{-8}$ mol $\mathrm{L}^{-1}$ FVX was spiked with FVX standard to furnish final concentrations of $4.0 \cdot 10^{-8}$, $6.0 \cdot 10^{-8}$, and $8.0 \cdot 10^{-8} \mathrm{~mol} \mathrm{~L}^{-1}$ (i.e. additions of 2.0, 4.0, and $6.0 \cdot 10^{-8} \mathrm{~mol} \mathrm{~L}^{-1}$ ). For the flow-injection method spikes of $1.5 \cdot 10^{-6}, 3.0 \cdot 10^{-6}$, and $4.5 \cdot 10^{-6}$ mol $\mathrm{L}^{-1}$ were added to a solution of the pharmaceutical with a FVX concentration of $3.5 \cdot 10^{-6} \mathrm{~mol} \mathrm{~L}^{-1}$, to obtain final concentrations of $5.0 \cdot 10^{-6}$, 6.5 $-10^{-6}$, and 8.0 $-10^{-6} \mathrm{~mol} \mathrm{\textrm {L } ^ { - 1 }}$ FVX.

\section{Results}

\section{Analysis of fluvoxamine using SWAdSV}

The electrochemical behaviour of FVX was studied under batch conditions by SWV and SWAdSV and it was verified that the analytical signal obtained decreased with increasing electrolyte $\mathrm{pH}$. A maximum peak current intensity $\left(i_{\mathrm{p}}\right)$, with a good repeatability, was obtained at $\mathrm{pH} 2$. At this $\mathrm{pH}$ FVX gave a reduction peak at approximately $-0.7 \mathrm{~V}$, which increased with increasing accumulation time $\left(t_{\text {acc }}\right)$ (Fig. 2,I). For a $1 \cdot 10^{-8} \mathrm{~mol} \mathrm{\textrm {L } ^ { - 1 }} \mathrm{FVX}$ solution this increase is significant for up to approximately $2 \mathrm{~min}$ (Fig. 2,II) at an optimised accumulation potential $\left(E_{\text {acc }}\right)$ of $-0.5 \mathrm{~V}$, after
Fig. 2 I Square wave voltammograms obtained from 5- $10^{-8} \mathrm{~mol} \mathrm{~L}^{-1}$ FVX solution. $E_{\text {acc }}=-0.5 \mathrm{~V} ; f=100$ $\mathrm{Hz}$;

$\mathrm{D} E_{\mathrm{s}}=3 \mathrm{mV} ; \mathrm{D} E_{\mathrm{p}}=30 \mathrm{mV}$; $t_{\mathrm{acc}}=(1) 0$, (2) 60 , and (3) $120 \mathrm{~s}$. II Effect of $t_{\text {acc }}$ on $i_{\mathrm{p}}$ for $1 \cdot 10^{-8} \mathrm{~mol} \mathrm{~L}^{-1} \mathrm{FVX}$ solution
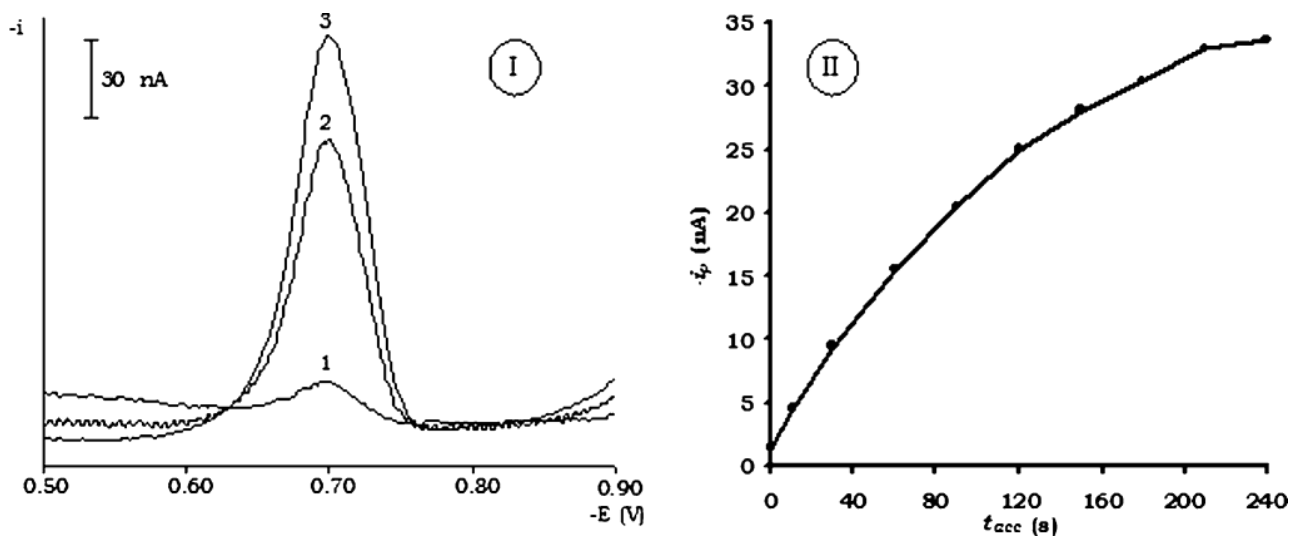
which the increase of $i_{\mathrm{p}}$ levels off, possibly because of saturation coverage of the drop and/or competitive adsorption.

Several experimental conditions related to the squarewave potential scan, for example frequency $(f)$, pulse step $\left(\mathrm{D} E_{\mathrm{s}}\right)$, and pulse amplitude $\left(\mathrm{D} E_{\mathrm{p}}\right)$, were studied and optimised to obtain maximum $i_{\mathrm{p}}$ and repeatability. These conditions are interrelated and have a combined effect on the analytical signal. Different values for $f(10-200 \mathrm{~Hz}), \mathrm{D} E_{\mathrm{s}}$ (1-8 mV), and $\mathrm{D} E_{\mathrm{p}}(10-50 \mathrm{mV})$ were used, and led to the optimum conditions: $f=200 \mathrm{~Hz}, \mathrm{D} E_{\mathrm{s}}=6 \mathrm{mV}$, and $\mathrm{D} E_{\mathrm{p}}=30$ $\mathrm{mV}$, in agreement with results obtained by Nevado et al. [40]. Although an optimum frequency of $200 \mathrm{~Hz}$ was established, several other fre- quencies were used throughout this work to obtain ei- ther better peak definition or linearity.

Variation of $i_{\mathrm{p}}$ with drug concentration $\left(C_{\mathrm{FVX}}\right)$, under the optimised conditions with a $t_{\text {acc }}$ of $30 \mathrm{~s}$, was represented by the straight-line equation $i_{\mathrm{p}}=(1.33 \pm 0.01) C_{\mathrm{FVX}}+(4.87 \pm 0.87) \cdot 10^{-9} \quad(r=0.999$; $n=14)$ within the linear range $6.00 \cdot 10^{-9}$ to 2.80 $-10^{-7} \mathrm{~mol} \mathrm{~L}^{-1}$ FVX. The LOD and LOQ were calculated and found to be $4.7 \cdot 10^{-9} \mathrm{~mol} \mathrm{~L}^{-1}$ and $1.6 \cdot 10^{-8} \mathrm{~mol} \mathrm{~L}^{-1}$, respectively. The results from assessment of the precision, expressed as the relative standard deviation (RSD), are listed in Table 1; they imply the method is precise. Furthermore, the recovery values shown in Table 1 indicate the method is accurate and selective for FVX determination.

In the application of the SWAdSV method to the quantification of FVX in Dumyrox, analyses were performed using a standard addition interval between 0 and $1.20-10^{-8} \mathrm{~mol} \mathrm{~L}^{-1}$ and a $t_{\mathrm{acc}}$ of $30 \mathrm{~s}$. The result obtained, $50.3 \pm 1.3 \mathrm{mg} \mathrm{FVX}$ maleate/tablet $(n=3)$, was in good agreement with the labelled value $(50 \mathrm{mg}$ FVX maleate/tablet) and with the result provided by the comparative UV method, 51.6 $\pm 1.0 \mathrm{mg}$ FVX maleate/ tablet $(n=3)$.

Table 2 shows the results obtained from application of the method to quantify FVX in six spiked serum samples, using standard additions and $f$ of $50 \mathrm{~Hz}$. The recovery was calculated to assess the accuracy of the method. Figure 3 shows the voltammograms obtained from a typical FVX analysis in human serum.

Table 1 Results from evaluation of the precision and accuracy of SWAdSV

\begin{tabular}{lcl}
\hline Property & $t_{\mathrm{acc}} 30 \mathrm{~s}$ & $t_{\mathrm{acc}} 60 \mathrm{~s}$ \\
\hline Repeatability (RSD \%) & $1.7(30)$ & $0.6(10)$ \\
& $0.9(100)$ & $1.3(40)$ \\
Intermediate precision (RSD \%) & $0.8(170)$ & $0.5(80)$ \\
& $1.9(10)$ & $2.1(10)$ \\
Recovery (\%) & $1.2(170)$ & $1.7(40)$ \\
& $98.6 \pm 1.8(20)$ & $98.2 \pm 2.2(20)$ \\
& $99.2 \pm 1.3(40)$ & $99.6 \pm 1.4(40)$ \\
& $99.5 \pm 0.9(60)$ & $98.6 \pm 0.5(60)$
\end{tabular}

Concentrations, in $\mathrm{nmol} \mathrm{L}^{-1}$, are given in parentheses
Table 2 Results from serum analysis (SWAdSV)

\begin{tabular}{llll} 
Sample & $\begin{array}{l}{[\mathrm{FVX}]_{\text {found }}} \\
\left(\mathbf{1} \mathrm{mol} \mathrm{L}^{-1}\right)\end{array}$ & $\begin{array}{l}{[\mathrm{FVX}]_{\text {added }}} \\
\left.(\mathbf{1 m o l ~ L})^{-1}\right)\end{array}$ & Recovery (\%) \\
\hline 1 & 1.23 & 1.57 & 78.3 \\
2 & 1.19 & & 75.8 \\
3 & 1.33 & & 84.7 \\
4 & 1.39 & & 88.5 \\
5 & 1.31 & 83.4 \\
6 & 1.24 & 79.0 \\
\hline
\end{tabular}

The possibility of avoiding time-consuming deoxygenation of the analysed solution was also studied. It was observed that dissolved oxygen did not interfere significantly when $t_{\mathrm{acc}}$ was $30 \mathrm{~s}\left(E_{\mathrm{acc}}=-0.5 \mathrm{~V}\right)$, even when low frequencies and concentrations $\left(10^{-8}\right.$ mol L ${ }^{-1}$ ) were used (Fig. 4).

The possibility of performing the measurements without the previous deoxygenation step enables signif- icant reduction of the analysis time and the possibility of including the HMDE in an FIA system, without prior or on-line oxygen removal, which leads to an increase in sample throughput.

\section{Analysis of fluvoxamine using FIA-SWAdSV}

On the basis of the previous results a single-manifold FIA system was developed in which the adsorption step at the HMDE was performed while the sample solution slug was flowing through the adapter head containing the mercury electrode [44]. The square wave voltam-

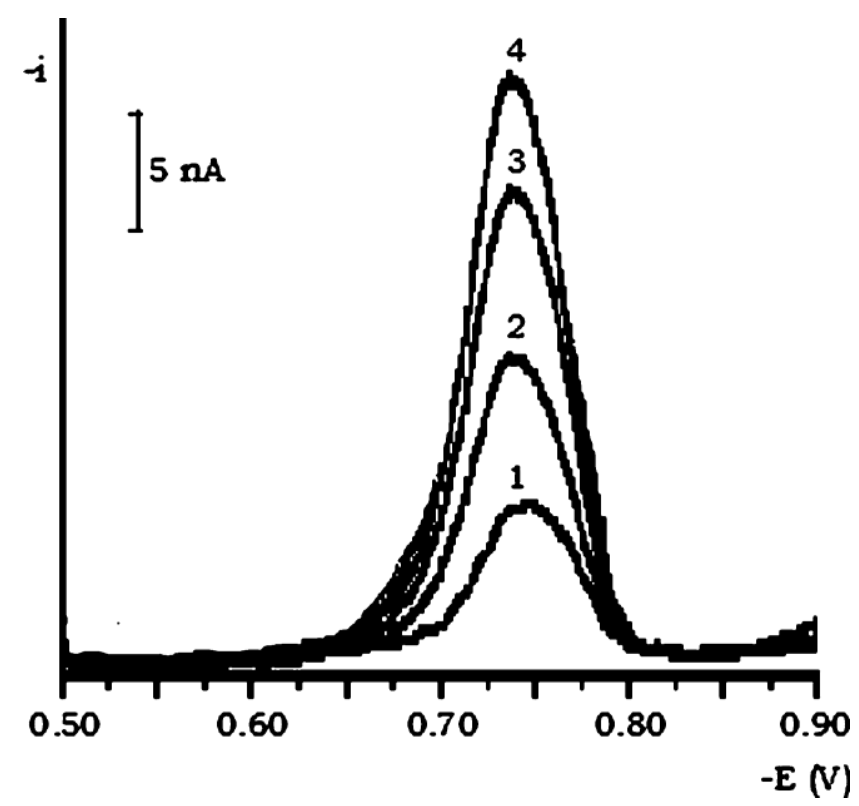

Fig. 3 Typical voltammograms obtained from FVX in a contaminated human serum sample after liquid-liquid extraction and using the standard addition method. Standard additions of FVX $\left(10^{-8} \mathrm{~mol} \mathrm{~L}^{-1}\right)$ : (1) 0; (2) 1.01 ; (3) 2.02; (4) 3.02. $E_{\text {acc }}=-0.5 \mathrm{~V}$; $t_{\mathrm{acc}}=30 \mathrm{~s} ; f=50 \mathrm{~Hz} ; \mathrm{D} E_{\mathrm{s}}=6 \mathrm{mV} ; \mathrm{D} E_{\mathrm{p}}=30 \mathrm{mV}$ 
Fig. 4 Effect of dissolved oxygen on the voltammetric determination of FVX. FVX concentration: (1) 0 ; (2) $5 \cdot 10^{-8}$; (3) $5 \cdot 10^{-7} \mathrm{~mol}$ $\mathrm{L}^{-1}$.

Deoxygenation time: I 600 and II 0 s. $E_{\text {acc }}=-0.5 \mathrm{~V} ; t_{\text {acc }}=30 \mathrm{~s}$; $f=50 \mathrm{~Hz} ; \mathrm{D} E_{\mathrm{s}}=6 \mathrm{mV}$;

$\mathrm{D} E_{\mathrm{p}}=30 \mathrm{mV}$
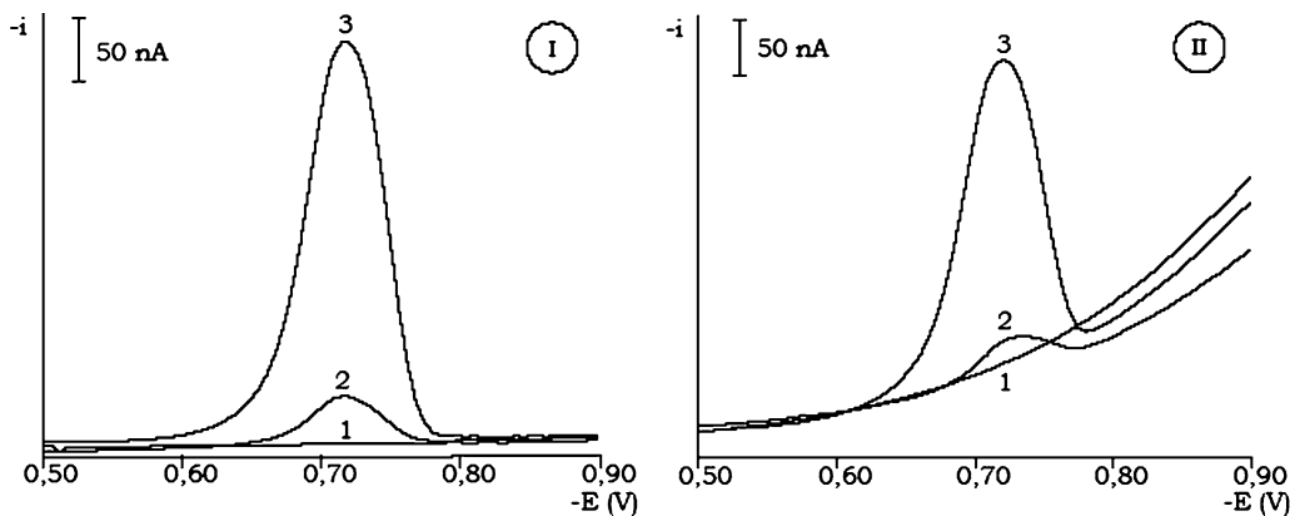

metric scan was also performed under flow conditions and no perturbation of the voltammetric signal because of the flow of electrolyte was observed. The length of the tube between the injection valve and the HMDE was kept as short as possible to minimise dispersion of the injected sample, and to keep the injected slug as intact as possible.

It was shown that flow rates up to about $1.4 \mathrm{~mL} \mathrm{~min}{ }^{-1}$ had no significant effect on $i_{\mathrm{p}}$ but that repeatability decreased slightly with increasing flow rate. A flow rate of $1.1 \mathrm{~mL} \mathrm{~min}{ }^{-1}$ was regarded as adequate for analysis of FVX, being a good compromise between sample throughput and repeatability. Using this flow rate, an injection volume of $500 \mathrm{LL}$ and a tube length of $50 \mathrm{~cm}$ between the injector and the detector, a constant concentration profile between \pm 20 and $35 \mathrm{~s}$ after injection was obtained (Fig. 5). The length of this zone depends on the injection volume and the flow rate, which can easily be controlled. The adsorption step and the voltammetric scan should be performed within this time interval.

By performing accumulation and measurement in the established interval, several experimental conditions of the voltammetric detection system were gradually opti- mised to obtain maximum sensitivity, repeatability and high sample throughput. The optimum $E_{\text {acc }}$ was found to be $-0.6 \mathrm{~V}$, at which an increase of $t_{\mathrm{acc}}$ from 0 to $5 \mathrm{~s}$ led to a marked increase of $i_{\mathrm{p}}$. For longer $t_{\mathrm{acc}}$ (up to $10 \mathrm{~s}$ ) $i_{\mathrm{p}}$ levels off, possibly because of saturation coverage of

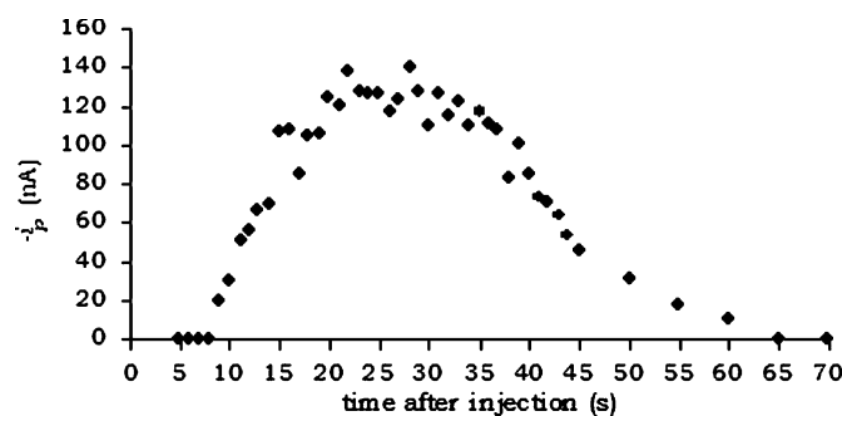

Fig. 5 Variation of $i_{\mathrm{p}}$ with time after sample injection for 1.0 $10^{-6} \mathrm{~mol} \mathrm{~L}^{-1} \mathrm{FVX}$ solution. $t_{\mathrm{acc}}=5 \mathrm{~s}$ the drop, competitive adsorption, or removal of species by the flow. A $t_{\text {acc }}$ of $5 \mathrm{~s}$ was regarded as suitable for use. Up to 120 samples per hour could be analysed using the proposed flow system.

Several frequencies $(50-400 \mathrm{~Hz}), \mathrm{D} E_{\mathrm{s}}(1-11 \mathrm{mV})$, and $\mathrm{D} E_{\mathrm{p}}(10-60 \mathrm{mV})$ were studied. The optimum conditions for determination of FVX were established as $f=250$ $\mathrm{Hz}, \mathrm{D} E_{\mathrm{s}}=7 \mathrm{mV}$, and $\mathrm{D} E_{\mathrm{p}}=30 \mathrm{mV}$.

Variation of $i_{\mathrm{p}}$ with $C_{\mathrm{FVX}}$, under the optimised conditions, was represented by the straight-line equation $i_{\mathrm{p}}=(0.378 \pm 0.005) C_{\mathrm{FVX}}-(2.54 \pm 2.83)-10^{-8} \quad(r=0.999$; $n=8)$ within the linear range $5.00 \cdot 10^{-7}$ to $1.00 \cdot 10^{-5} \mathrm{~mol} \mathrm{~L}^{-1}$ FVX. The LOD and LOQ were found to be $4.4 \cdot 10^{-7}$ and $1.5 \cdot 10^{-6} \mathrm{~mol} \mathrm{~L}^{-1}$, respec- tively. Results from evaluation of precision, expressed as the relative standard deviation (RSD), are listed in Ta-ble 3; they imply the method is precise. From the recovery values shown in Table 3 it can be concluded that the method is accurate and selective for FVX determination.

To evaluate the adequacy of the method it was applied to the quantification of FVX in Dumyrox. Typical flow-injection voltammograms obtained during quantification of FVX in Dumyrox are shown in Fig. 6. The result, 55.0 $\pm 2.2 \mathrm{mg} \mathrm{FVX}$ maleate/tablet $(n=3)$, is in good agreement with the labelled value $(50 \mathrm{mg}$ FVX maleate/tablet) and with the result obtained from a UV

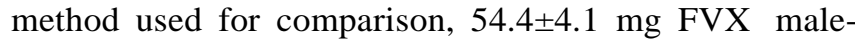
ate/tablet $(n=3)$.

Table 3 Results from evaluation of the precision and accuracy of FIA-SWAdSV

Property

\begin{tabular}{lc}
\hline Repeatability (RSD \%) & $1.2(2.0)$ \\
& $1.1(5.0)$ \\
Intermediate Precision (RSD \%) & $1.6(8.0)$ \\
& $2.4(2.0)$ \\
Recovery (\%) & $2.1(5.0)$ \\
& $1.6(8.0)$ \\
& $101.2 \pm 4.9(1.5)$ \\
$99.3 \pm 4.0(3.0)$ \\
$100.2 \pm 0.9(4.5)$
\end{tabular}

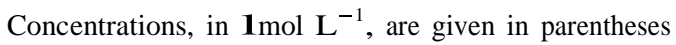




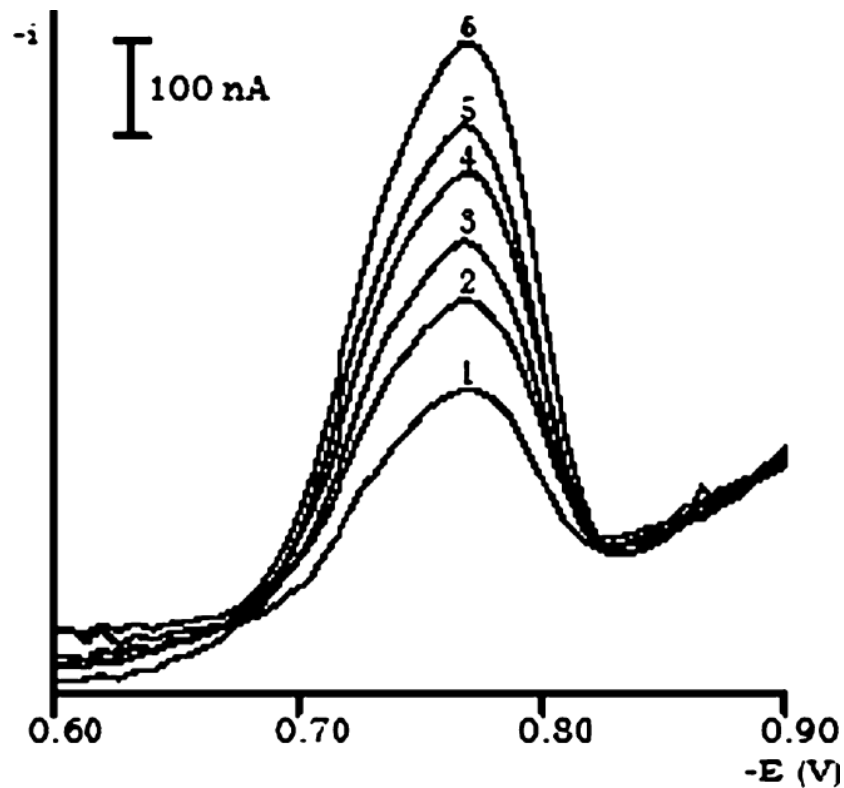

Fig. 6 Typical flow-injection voltammograms obtained for FVX in Dumyrox using the standard addition method. Standard additions of FVX (10 ${ }^{-7} \mathrm{~mol} \mathrm{~L}^{-1}$ ): (1) 0; (2) 2.00; (3) 4.00; (4) 6.00; (5) 8.00; (6) 10.0. $E_{\mathrm{acc}}=-0.6 \mathrm{~V} ; t_{\mathrm{acc}}=5 \mathrm{~s} ; f=250 \mathrm{~Hz} ; \mathrm{D} E_{\mathrm{s}}=7.05 \mathrm{mV}$; $\mathrm{D} E_{\mathrm{p}}=30 \mathrm{mV}$; flow rate $=1.1 \mathrm{~mL} \mathrm{\textrm {min } ^ { - 1 }}$

\section{Conclusions}

On the basis of the electrochemical behaviour of FVX, SWAdSV and FIA-SWAdSV analytical methods have been developed for quantification of the drug in a pharmaceutical product and in spiked human serum. Both methods can be applied as good alternatives to the chromatographic methods used for determination of FVX in pharmaceutical preparations. For quantification of FVX in serum further optimisation is needed to compete with the techniques most widely used for this analysis. Both methods have the advantages of high sample throughput and significantly reducing analysis time and cost.

Further investigation is being undertaken to determine FVX in biological samples using on-line sample extraction and the HMDE flow cell as an HPLC detector.

Acknowledgements The authors thank Solvay Pharmaceuticals for providing the fluvoxamine maleate standard. One of the authors (Henri P.A. Nouws) thanks the PRODEP III program for his Ph.D. grant.

\section{References}

1. Solvay Pharmaceuticals (1999) Fluvoxamine Monograph

2. De Vane CL (1999) Cell Mol Neurobiol 19:443-466

3. Hiemke C, Hä rtter S (2000) Pharmacol Ther 85:11-28

4. Duverneuil C, Grandmaison GL, Mazancourt P, Alvarez JC (2003) Ther Drug Monit 25:565-573
5. Titier K, Castaing N, Gomez ES, Pehourcq F, Moore N, Molimard M (2003) Ther Drug Monit 25:581-587

6. Frahnert C, Rao ML, Grasma“ der K (2003) J Chromatogr B 794:35-47

7. Ohkubo T, Shimoyama R, Otani K, Yoshida K, Higuchi H, Shimizu T (2003) Anal Sci 19:859-864

8. Berzas JJ, Guiberteau C, Contento AM, Rodriguez V (2002) Chromatographia 56:545-551

9. Dallet P, Labat L, Richard M, Langlois MH, Dubost JP (2002) J Liq Chromatogr Related Technol 25:101-111

10. Tournel G, Houdret N, Hedouin V, Deveaux M, Gosset D, Lhermitte M (2001) J Chromatogr B 761:147-158

11. Skibinski R, Misztal G, Olajossy M (2000) Chem Anal Warsaw 45:815-823

12. Palego L, Marazziti D, Biondi L, Giannaccini G, Sarno N, Armani A, Lucacchini A, Cassano GB, Dell'Osso L (2000) Ther Drug Monit 22:190-194

13. Bagli M, Rao ML, Sobanski T, Laux G (1997) J Liq Chromatogr Related Technol 20:283-295

14. Belmadani A, Combourieu I, Bonini M, Creppy EE (1995) Hum Exp Toxicol 14:34-37

15. Ha rtter S, Wetzel H, Hiemke C (1992) Clin Chem 38:2082-2086

16. Vandermeerschmougeot V, Diquet B (1991) J Chromatogr Biomed Appl 567:441-449

17. Foglia JP, Birder LA, Perel JM (1989) J Chromatogr Biomed Appl 495:295-302

18. Gutteck U, Rentsch KM (2003) Clin Chem Lab Med 41:15711579

19. Kollroser M, Schober C (2003) Chromatographia 57:133-138

20. Lucca A, Gentilini G, Silva SL, Soldarini A (2000) Ther Drug Monit 22:271-276

21. Pullen RH, Fatmi AA (1992) J Chromatogr Biomed Appl 574:101-107

22. Schweitzer C, Spahn H, Mutschler E (1986) J Chromatogr 382:405-411

23. Nevado JJB, Salcedo AMC, Llerena MJV, Nuevo EA (2000) Anal Chim Acta 417:169-176

24. Flores JR, Nevado JJB, Salcedo AMC, D1' az MPC (2004) J Sep Sci 27:33-40

25. Labat L, Deveaux M, Dallet P, Dubost JP (2002) J Chromatogr B 773:17-23

26. Buzinkaiova' T, Polonsky' J (2000) Electrophoresis 21:2839-2841

27. Rodri' guez J, Berzas JJ, Contento AM, Cabello MP (2003) J Sep Sci 26:915-922

28. Nevado JJB, Llerena MJV, Salcedo AMC, Nuevo EA (2000) J Chromatogr Sci 38:200-206

29. Eap CB, Gaillard N, Powell K, Baumann P (1996) J Chromatogr B 682:265-272

30. Rotzinger S, Todd KG, Bourin M, Coutts RT, Baker GB (1997) J Pharm Toxicol Med 37:129-133

31. Starczewska B, Jasinska A, Bialous B (2003) Pharmazie $58: 245-248$

32. Starczewska B (2001) J Trace Microprobe Tech 19:19-24

33. Starczewska B, Mielech K (2000) J Pharm Biomed Anal 23:243-247

34. Starczewska B, Tarasiewicz HP, Baranowska K (2000) J Pharm Biomed Anal 23:477-481

35. Atmaca S, Tatar S (1994) Pharmazie 49:458-459

36. Alhaider AA, Hagga MEM, Alawady ME, Gadkariem EA (1993) Anal Lett 26:887-901

37. Deubner R, Holzgrabe U (2002) Magn Reson Chem 40:762766

38. Elmali F, Alpdogan G, Sungur S, Aycan S (2000) Turk J Chem 24:299-302

39. Tunc el M, Altiokka G, Atkosar Z (1994) Anal Lett 27:1135- 1145

40. Nevado JJB, Flores JR, Penalvo GC (2000) Electroanalysis 12:1059-1063

41. Wang J (1985) Stripping analysis: principles, instrumentation and applications. VCH Publishers, Deerfield Beach, USA, pp $61-63$ 
42. Ramaley L, Dalziel JA, Tan WT (1981) Can J Chem 59:33343340

43. Barros AA, Rodrigues JA, Almeida PJ, Rodrigues PG, Fogg AG (1999) Anal Chim Acta 385:315-323

44. Rodrigues JA, Barros AA, Almeida PJ, Rodrigues PG, Fogg AG (2001) Anal Chim Acta 449:119-127
45. The United States Pharmacopoeia (2000) The National Formulary, USP 24, NF 19, USP Convention, 12601, Rockville, MD, pp 2149-2151

46. Miller JN, Miller JC (2000) Statistics and chemometrics for analytical chemistry, 4th edn. Prentice Hall, London, pp 116-123 